\title{
A New Species of the Genus Helicotylenchus (Nematoda: Hoplolaimidae) \\ Attacking Sugarcane
}

\author{
Jessé Román \\ INTRODUCTION
}

Examinations of soil samples collected from around the roots of sugarcane at different localities throughout the Island of Puerto Rico, reveal the presence of large numbers of plant-parasitic nematodes. Spiral nematodes of the genus Helicotylenchus, are among those most frequently encountered.

Recently the author was called upon to make a study of the nematode population present in the sugarcane fields at Central Soller, San Sebastian, P.R. The soil and root samples collected at this locality revealed very high populations of different nematode genera, of which specimens of Helicotylenchus were the most numerous. Our attention was attracted by a form which undoubtedly represents a new species of this group of spiral nematodes. Its description is here presented.

\section{HELICOTYLENCHUS CONCAVUS N.Sp.}

MATERIAL 16 females

MEASUREMENTS $\mathrm{L}=0.63-0.78 \mathrm{~mm}$; $\mathrm{a}=26.6-32.7 \mu ; \mathrm{b}=5.9-8.6 \mu$; c $=40.4-52.4 \mu ; \mathrm{V}=58-66$ percent; stylet $28-29 \mu$; phasmids at $32-40 \mu$ from tail end; dorsal pharyngeal gland opening at $13-14 \mu$ from base of stylet.

DESCRIPTION Body tapering at both extremities, anteriad of intestine and posteriad of anus. Head marked by 4 annules, continuous with body contour. Cuticle plainly annulated; annules broad and convex, interrupted by the lateral fields which have 4 incisures, the 2 internal ones joining together at the 9th to 10th annule behind anal opening; incisures beginning slightly behind base of stylet, ending in front of tail end, central strip slightly wider than edging ones. Phasmids variable in position, but always located anteriad to the latitude of the anal opening at 32 to $40 \mu$ from tail end. Cervical papillae not seen. Tail with broadly rounded terminus, and annulation following tail contour; slightly concave dorsally as shown in figure 1, D. Hemizonid 3 annules in front of excretory pore. Excretory canal with a collaret as shown in figure 1, A. Head narrower than body. Cephalic

1 Assistant Nematologist, Agricultural Experiment Station, University of Puerto Rico, Río Piedras, P.R. The writer wishes to express his apprecintion to Dr. G. Steiner, of this Station for his guidance and encouragement during the preparation of this paper. 


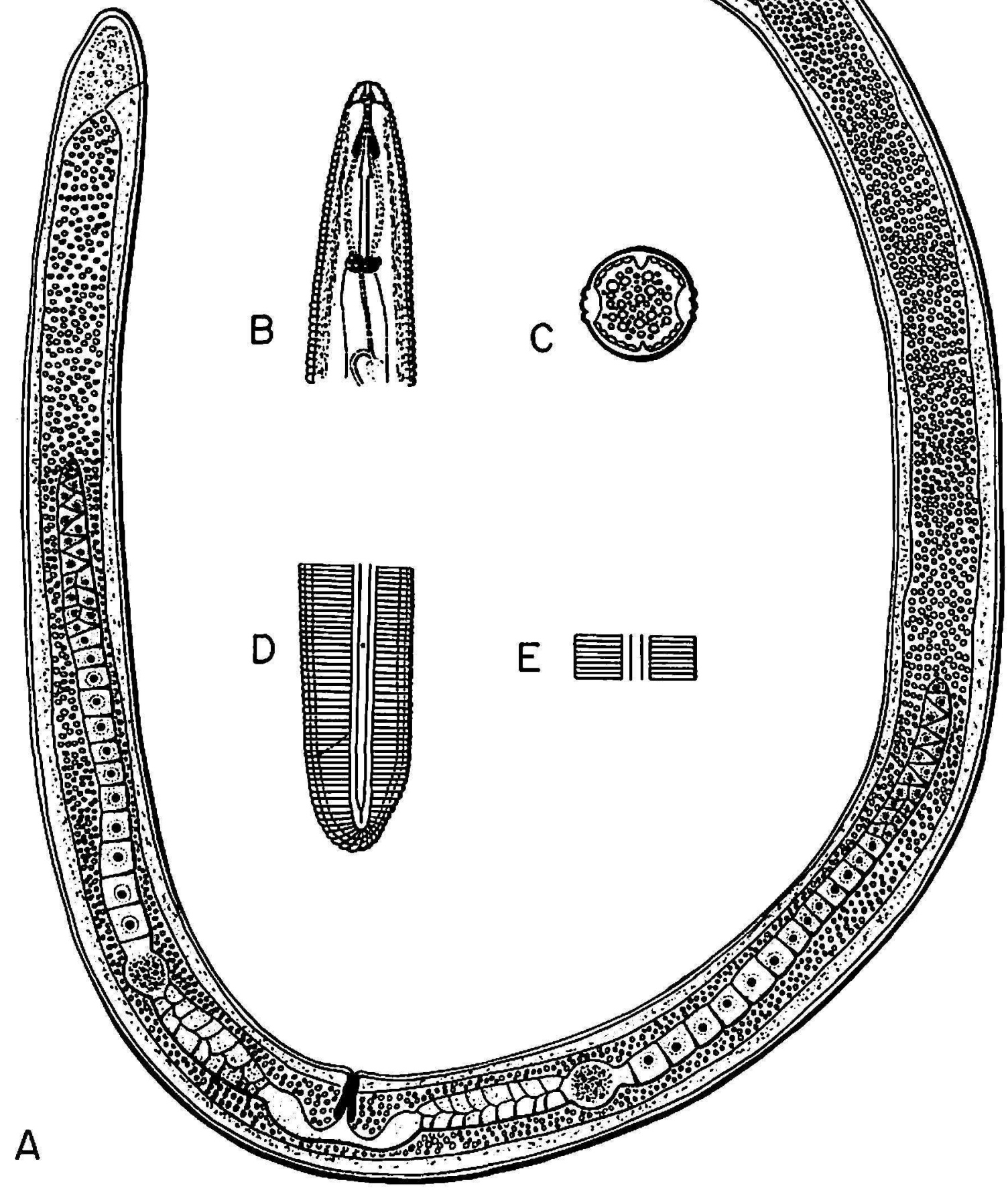

Fı. 1.-Helicolylenchus concavus: A, Female; $\times 540 ; B$, head end, $\times 720 ; C$, cross section of body at a region posteriad of pharyngeal glands and anteriad of right ovary, $\times 720 ; \mathrm{I}$, tail end, $\times 720 ; \mathrm{E}$, lateral field, $\times 720$. 
framework prominent. Buccal stylet of adult 28 to $29 \mu$ long, its knobs slightly concave anteriorly. Protrudor muscles of stylet attached to vestibulum framework. Median pharyngeal bulb ovoid to spherical, with a conspicuous valvular apparatus. Nerve ring at about center of isthmus. Glandular lobe of pharynx variable in size, but always overlapping intestine. Outlet of dorsal pharyngeal gland 13 to $14 \mu$ behind stylet (i.e. about half the length of the stylet). Intestine granulated. Vulva a transverse slit at 58 to 66 percent of total length, without lateral flaps. Vagina with cuticularized reinforcement in the wall. Ovaries outstretched on either the right or left side of intestine, but always on the same side. Oocytes in single file except for a short region close to the distal end. Conspicuous spermathecae present.

HOLOTXPE Female collected on April 8, 1961, in the sugarcane fields at Central Soller, San Sebastián, Puerto Rico. Slide No. 1 author's collection. MALE Not known.

PARATYPES Slides Nos. 2, 3, 4, and 5 author's collection, also vial No. 1 deposited in the collection of the Section of Nematology, Department of Entomology, of this Station.

TYPE LOCALiTy Sugarcane fields at Central Soller, San Sebastián, P.R. TYPE HOST Sugarcane, Saccharum officinarum $\mathrm{L}$.

DIAGNOSIS Helicotylenchus concavus n.sp. resembling Helicotylenchus platyurus, Perry, 1959, but different by smaller size (only 0.63 to $0.78 \mathrm{~mm}$. as compared to 0.85 to $0.94 \mathrm{~mm}$. in $H$. platyurus), a shorter stylet (only 28 to $29 \mu$ as compared to 30 to $34 \mu$ in $H$. platyurus), and by a slight concavity at the dorsal side of tail. It is different from all other species of the genus by the fusion of the two internal incisures of the lateral fields at the 9th to 10th annule posteriad of anus, further by a collaret in the wall of the excretory canal close to its opening, and by cuticularized reinforcement in the wall of the vagina.

Helicotylenchus concavus derives its specific name from its characteristically slight concavity on the dorsal side of tail.

\section{SUMMARY}

Sugarcane in Puerto Rico is attacked by high populations of plant parasitic nematodes, of which specimens belonging to the genus Helicotylenchus are among the most numerous. A new species of this genus was found at Central Soller, San Sebastian, P.R. A description of the nematode, as well as a plate illustrating the same are given in this article.

\section{RESUMEN}

Gran número de nematodos parasíticos atacan la caña de azúcar en Puerto Rico, de los cuales las especies del género Helicotylenchus son de las 
más numerosas. Una nueva especie de este género se encontró en Central Soller, San Sebastián, Puerto Rico. Aquí en este artículo se describe y se ilustra esta especie.

\section{LITERATURE}

1. Carvalho, J. C., Helicotylenchus nannus (description of the male) and Rotylenchus iperoiguensis n.sp., Rev. do Inst: Adolfo Lutz 16 142-7, 1956.

2. - Rotylenchus elisensis, nova specie associada com raízes de soja, Rev. do Inst. Aldofo Lutz 17 43-6, 1957.

3. - Helicotylenchus elisensis n.comb. (Nematoda: Tylenchidae), Arq. do Inst. Biol. 26 45-8, 1959.

4. Cobb, N. A., Nematodes mostly Australian and Fijian, Linn. Soc. N.S. Wales, Macleay Memorial Volume, 252-308, 1893.

5. Golden, A. M., Taxonomy of the Spiral Nematodes (Rotylenchus and Helicotylenchus), and the Developmental Stages and Host-Parasite Relationships of $R$. buxophilus, n.sp. Attacking Boxwood, Univ. Md. Bul. A-85, pp. 1-28, 1956.

6. Goodey, T., The genus Anguillulina Gerv. and v. Ben., 1859, vel Tylenchus Bastian, 1865, J. Helminth. 10 75-180, 1932.

7. - On Anguillulina multicincta (Cobb) and other species of Anguillulina associated with the roots of plants, J. Helminth. 18 21-38, 1940.

8. Lordello, L. G. E., Rotylenchus melancholicus, n.sp. found associated with grass roots, and its sexual dimorphism, J.Wash. Acad. Sci. 45 81-3, 1955.

9. Perry, V. G., Anatomy, Taxonomy, and Control of Certain Spiral Nematodes Attacking Blue Grass in Wisconsin, Univ. Wis., Res. Bul. 207 pp. 1-24, 1959.

10. Steiner, G., Helicotylenchus, a new genus of plant-parasitic nematodes and its relationship to Rolylenchus (Filipjev), Proc. Helminth. Soc. Wash. 12 (2) 34-8, 1945. 